\title{
Perangkat Visualisasi Interaktif Sebagai Media Terapi, Alat Bantu Komunikasi, dan Pembelajaran Bagi Penderita Autism Spectrum Disorder
}

\author{
Evans Fuad $^{1}$, Rahmad Gunawan ${ }^{2}$, Fitri Indra Yani ${ }^{3}$ \\ 1,2,3Institution/affiliation \\ (Fakultas Ilmu Komputer Universitas Muhammadiyah Riau, Program Studi Teknik Informatika) \\ (Jl. Tambusai Ujung, Pekanbaru, Riau, telp. 08521304 4947) \\ e-mail: 1evansfuad@umri.ac.id, ${ }^{2}$ rahmadgunawan@umri.ac.id, ${ }^{3}$ fitriindrayani@umri.ac.id
}

\begin{abstract}
Abstrak
Autism Spectrum Disorder merupakan suatu gangguan perkembangan secara menyeluruh yang mengakibatkan hambatan dalam kemampuan sosialisasi, komunikasi, dan juga perilaku. Area utama gangguan yang dialami pasien Autisme adalah gangguan dalam bidang interaksi sosial, gangguan dalam bidang komunikasi (verbal-non verbal), gangguan dalam bidang perilaku, gangguan dalam bidang perasaan dan emosi, dan gangguan dalam bidang persepsi-sensorik, serta minat berulang. Sebagian besar penelitian menemukan bahwa mayoritas individu dengan Autisme (75\%) cacat intelektual, dengan kira-kira setengah dalam kisaran retardasi mental ringan hingga sedang, dan setengah dalam rentang yang berat sampai sangat dalam[1]. Tujuan dari penelitian ini adalah membangun sebuah aplikasi mobile sebagai alat bantu (tools) komunikasi, pembelajaran dan terapi yang dirancang menggunakan metode Augmentative and Alternative Communication, yang dapat digunakan pihak pendidik maupun orang tua, serta pasien Autisme dengan gangguan komunikasi, untuk dapat diterapkan sebagai salah satu tools dalam menunjang dan mengoptimalkan komunikasi dan metode terapi demi terwujudnya kemandirian.
\end{abstract}

Kata kunci: Augmentative and Alternative Communication, Autism Spectrum Disorder, Autisme, Komunikasi, Mobile

\begin{abstract}
Autism Spectrum Disorder is a complete development that addresses challenges in socialization, communication, and behavior skills. The main areas related to Autism sufferers are disorders in the social field, disorders in the field of communication (verbal-non verbal), disorders in the field of relationships, disorders in the field of feelings and change, and monitoring in the field of perception-sensory, and recurring interests. Most studies have found the contribution of individuals with Autism (75\%) with intellectual disabilities, with about half of moderate mental retardation rates, and half in severe to very deep ranges [1]. The purpose of this research is to develop a mobile application as a communication, learning and therapeutic tool designed using Augmentative and Alternative Communication methods, which can be used as educators and parents, as well as Autism patients with communication communication, can used as one of the tools used to support and optimize communication and therapeutic methods according to the realization of independence.
\end{abstract}

Keywords: Augmentative and Alternative Communication, Autism Spectrum Disorder, Autism, Communication, Mobile.

\section{PENDAHULUAN}

Autism Spectrum Disorder (ASD) merupakan suatu gangguan perkembangan secara menyeluruh yang mengakibatkan hambatan dalam kemampuan sosialisasi, komunikasi, dan juga perilaku. Area utama 
gangguan yang dialami pasien Autisme adalah gangguan dalam bidang interaksi sosial, gangguan dalam bidang komunikasi (verbal dan non-verbal), gangguan dalam bidang perilaku, gangguan dalam bidang perasaan dan emosi, dan gangguan dalam bidang persepsi-sensorik, serta minat berulang. Sebagian besar penelitian menemukan bahwa mayoritas individu dengan Autisme (75\%) cacat intelektual, dengan kira-kira setengah dalam kisaran retardasi mental ringan hingga sedang, dan setengah dalam rentang yang berat sampai sangat dalam [1].

Kementrian Kesehatan Republik Indonesia pada tahun 2015, mencatat satu dari 250 anak di Indonesia mengalami gangguan Autisme dan terdapat kurang lebih 12.800 anak dengan Autisme di Indonesia [2]. Augmentative and alternative communication (AAC) merupakan media serta cara yang digunakan oleh anak yang mengalami hambatan dalam berkomunikasi, agar dapat berkomunikasi dengan baik dan lancar dengan orang di sekitarnya. Metode ini berupa petunjuk dalam bentuk gambar-gambar dan simbol, yang memudahkan penderita Autisme dan orang tua melakukan komunikasi, dan memudahkan dalam melakukan aktifitas sehari-hari.

Penelitian 30-50 \% anak dengan ASD tidak berbicara dan cenderung visual. Dalam hal ini penelitian membuktikan bahwa AAC dapat meningkatkan kualitas hidup anak-anak yang didiagnosis dengan ASD dan non-verbal, dengan mendukung dan meningkatkan komunikasi mereka. Dengan alat bantu media pembelajaran dan terapi yang masih menggunakan buku maupun alat bantu lainnya yang kurang efektif dalam hal biaya, serta pembelajaran menggunakan media buku atau gambar yang selalu dalam keadaan diam (tidak bergerak, tidak aktif, dan tidak berubah keadaannya), membuat pasien Autisme mudah bosan dan sulit dalam melaksanakan kegiatan terapi dan memahami materi yang diberikan dalam proses pembelajaran [3].

Identifikasi Masalah: a. Beberapa orang tua pasien penderita Autisme mengalami kesulitan untuk berkomunikasi dan melakukan interaksi kepada anaknya, sehingga tidak dapat untuk memberikan pembelajaran kepada anaknya di luar waktu terapi.

b. Alat bantu belajar anak seperti alat peraga, buku, kartu huruf dan angka akan banyak memakan biaya, serta orang tua yang tidak memiliki alat peraga di rumah tidak dapat memberikan pembelajaran kepada anaknya.

c. Pembelajaran melalui media buku yang cenderung selalu dalam keadaan diam (tidak bergerak, tidak aktif, tidak berubah keadaannya), membuat penderita Autisme mudah bosan dan sulit memahami materi yang diberikan.

d. Kurangnya aplikasi multimedia yang menyediakan beragam fungsi (komunikasi, pembelajaran, dan terapi) dalam satu aplikasi untuk anak Autisme.

Tujuan penelitian ini membangun sebuah aplikasi sebagai tools komunikasi, pembelajaran dan terapi yang dirancang menggunakan metode AAC, yang dapat digunakan pihak pendidik maupun orang tua, serta pasien Autisme dengan gangguan komunikasi, untuk dapat diterapkan sebagai salah satu tools dalam menunjang dan mengoptimalkan komunikasi dan metode terapi demi terwujudnya kemandirian.

Berdasarkan permasalahan tersebut, maka urgensi dalam penelitian ini adalah menyediakan alat bantu dengan memanfaatkan teknologi media digital, melalui rancangan suatu produk mobile berupa alat bantu komunikasi (tools) yang dirancang menggunakan metode AAC, agar dapat digunakan oleh pihak pendidik serta orang tua, sehingga dapat membantu anak penderita autisme menajadi mandiri.

\section{Autisme}

Gangguan Autisme atau Autism Spectrum Disorder merupakan gangguan perkembangan fungsi otak yang kompleks dan sangat bervariasi (spektrum). Biasanya gangguan perkembangan ini meliputi 
bidang komunikasi, interaksi, perilaku, emosi dan sensoris [4].

Sebagaimana ditentukan dalam DSM-IV-TR (American Psychiatric Association, 2000) bahwa gangguan Autisme melibatkan keterbatasan dalam keterkaitan sosial, komunikasi verbal dan non-verbal dan berbagai minat dan perilaku. Dalam domain sosial, gejala termasuk gangguan penggunaan perilaku verbal (misalnya kontak mata, ekspresi wajah, gerakan tubuh) untuk mengatur interaksi sosial, kegagalan untuk mengembangkan hubungan sebaya yang sesuai usia. Dalam domain perilaku dan minat, sering ada perilaku yang tidak biasa, kepatuhan tidak fleksibel untuk rutinitas non-fungsional, stereotip gerakan tubuh seperti mengepakkan tangan, jentik-jentik di depan mata, ketika berjalan dan keasyikan dengan bagian-bagian atau modalitas sensoris benda [1].

ASD sementara pelatihan peer berfokus pada menguasai keterampilan meniru dan perhatian sebagai keterampilan dasar, sambil berfokus pada rangsangan visual yang dicintai, yang menarik perhatian anak Autisme dan membuatnya berpartisipasi secara positif dalam program pelatihan, serta membantunya mengatur lingkungan di mana interaksi dengan teman sebaya terjadi, dan pengulangannya selama sesi pelatihan oleh sebagian rekan [5].

\section{Terapi Pasien Autisme}

Dalam bidang medis, kata terapi sinonim dengan kata pengobatan. Di antara psikolog, kata ini mengacu kepada psikoterapi. Terapi pencegahan atau terapi Profilaksis adalah pengobatan yang dimaksudkan untuk mencegah munculnya kondisi medis. Sebagai contoh banyaknya vaksin untuk mencegah infeksi penyakit. Terapi abortive merupakan pengobatan yang dimaksudkan untuk menghentikan kondisi medis dari perkembangan lebih lanjut. Pengobatan yang dilakukan pada tkita-tkita paling awal dari munculnya penyakit, seperti gejala sakit kepala migrain, adalah sebuah terapi abortive. Sedangkan Terapi supportive merupakan suatu terapi yang tidak merawat atau memperbaiki kondisi yang mendasarinya, melainkan meningkatkan kenyamanan pasien [1].

Autisme seperti gangguan perkembangan neurokognitif lainnya umumnya "tidak dapat disembuhkan". Tujuan utama perawatan dan terapi adalah meminimalkan fitur inti dan defisit terkait, memaksimalkan kemandirian fungsional dan kualitas hidup. Agar tujuan ini tercapai, kita perlu memfasilitasi pengembangan dan pembelajaran yang mendidik, mempromosikan sosialisasi, mengurangi masalah perilaku dan psiko dan mendukung keluarga. Idealnya, proses pembelajaran dan terapi harus membantu mengurangi fitur inti Autisme seperti gangguan dalam sosial timbal balik, defisit dalam komunikasi, dan pembatasan, pola perilaku berulang [1].

\section{Augmentative and Alternative Communication (AAC)}

AAC merupakan metode dan teknologi yang digunakan untuk mengimbangi individu dalam kompetensi komunikasi, dalam hal ini AAC bisa bersifat sementara atau permanen [3].

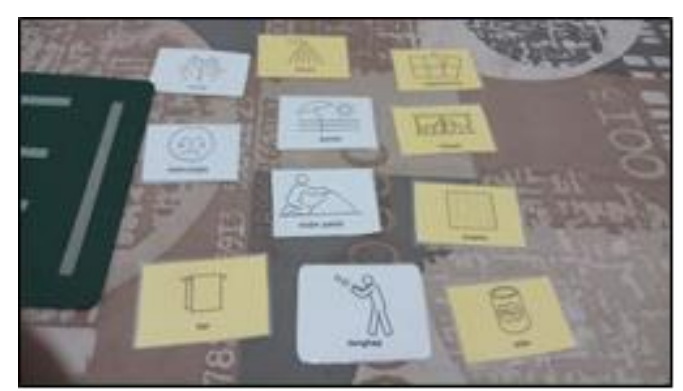

Gambar 1. Contoh Simbol dan gambar AAC Dasar

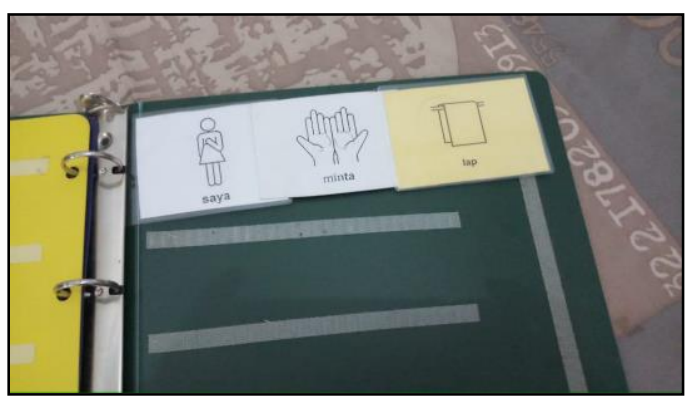


Gambar 2. Contoh Tahapan AAC Bahasa Ekspresif

AAC merupakan alat yang digunakan dalam melakukan komunikasi pada anak dengan berkebutuhan khusus, seperti pada anak dengan Autisme.

1. Teknik komunikasi

- Teknik komunikasi tanpa bantuan Teknik ini tidak memerlukan alat bantu dari luar diri anak dan tidak pula memerlukan prosedur khusus dalam pengunaannya. Teknik ini menggunakan kaidah berbicara, bahasa isyarat, gesture, dan mimik muka. Kelebihan teknik ini adalah tidak perlu alat Bantu, dengan sendirinya menjadi lebih murah karena tidak memerlukan biaya, dan mudah ditukar atau dipindahkan. Adapun kekurangannya adalah: pertama, tidak inovatif sehingga komunikasi di masa depan akan menjadi masalah karena bahasa komunikasi itu terus berkembang; kedua, tergantung pada kemampuan ingatan pengguna, ketiga isyarat sebenarnya sulit dipelajari [1].

- Teknik komunikasi dengan bantuan

Teknik ini memerlukan alat Bantu dan menggunakan prosedur secara rinci dalam penggunaannya. Baik alat Bantu ini elektronik maupun non-elektronik maupun sistem simbol. Alat bantu ini dari yang sangat sederhana sampai yang paling canggih, dari papan komunikasi sampai alat bantu bicara sintetik yang menggunakan komputer. Jadi teknik ini memerlukan objek fisik yang berupa peralatan bantu komunikasi untuk memudahkan seorang anak berkomunikasi. Kelebihan teknik ini adalah dapat menyampaikan pesan lebih kompleks terhadap kemampuan berbahasa/berkomunikasi bagi pengguna, dan dapat digunakan komunikasi jarak jauh. Adapun kelemahan teknik ini adalah mudah rusak, kehilangan daya (elektronik), perawatan susah, dan lebih mahal.

2. Sistem simbol

Berbagai sistem simbol telah dibuat dari benda asli (benda sebenarnya), berbentuk gambar, dan sistem simbol yang abstrak. Sistem simbol yang abstrak antara lain gambar yang mewakili suatu bentuk atau kejadian (picturial representations), ideographs (ide yang ditampilkan melalui simbol grafis), simbol arbitrari (ide dalam bentuk konfigurasi garis arbitrari), dan lexigrams (simbol visual-grafis secara arbitrari yang merupakan bentuk-bentuk geometrik).

3. Kemampuan berkomunikasi

Prosedur dan alat bantu AAC telah menyediakan peluang terbaik bagi individu yang tidak mampu berkomunikasi secara lisan/verbal untuk dapat berkomunikasi dengan orang lain secara baik. Oleh karena itu porsedur dan alat bantu AAC harus digunakan secara optimal.

Pada anak dengan Autisme sering mengalami kesulitan dalam berbicara. Kurang lebih sekitar 50\% dari anak autis tidak berbicara, mereka cenderung sangat visual. Di beberapa Negara berkembang, sekolah khusus dengan anak Autisme telah menggunakan dan memasukkan program AAC. Visual yang baik menggunakan komunikasi visual atau voice-output communication aid [3].

AAC dapat menjadi cara yang efektif bagi anak untuk belajar kata-kata awal, karena mereka menaruh kata yang diucapkan bersamaan dengan gambar atau isyarat yang mewakili kata tersebut, misalnya, dengan mengatakan 'apel' dan menahan gambar apel. Menggunakan prompt visual dapat mendorong anak untuk melakukan kontak mata dengan mendapatkan perhatian mereka.

Diperkirakan bahwa antara 30 dan $50 \%$ dari individu dengan ASD, tidak menggunakan komunikasi fungsional. Ada bukti yang menunjukkan bahwa komunikasi AAC dapat meningkatkan kualitas hidup anak-anak yang didiagnosis dengan ASD dan non verbal, serta meningkatkan komunikasi mereka [3]. Setiap anak-anak berkebutuhan khusus memerlukan pendidikan yang lebih khusus, sehingga dapat disesuaikan dengan hambatan-hambatan belajar serta kebutuhan masing-masing anak secara individual [7]. 


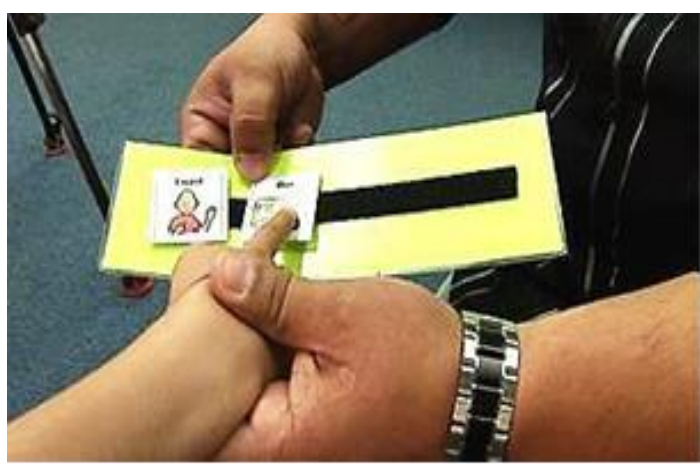

Gambar 3. Metode AAC pra verbal

Tabel 1. Program Latihan Kemandirian

\begin{tabular}{|c|l|}
\hline No & \multicolumn{2}{|c|}{ Berbasis gambar/simbol } \\
\hline 1 & $\begin{array}{l}\text { Mengerti gambar dan asosiasi } \\
\text { (gambar/fungsi/tugas/kategori) } \\
\text { konsep minimal 400-500 } \\
\text { konsepbelajar dengan gambar }\end{array}$ \\
\hline 2 & $\begin{array}{l}\text { Menyatakan keinginan dengan } \\
\text { makanan }\end{array}$ \\
\hline 3 & $\begin{array}{l}\text { Menyatakan keinginan dengan } \\
\text { minuman }\end{array}$ \\
\hline 4 & $\begin{array}{l}\text { Menyatakan keinginan dengan kata } \\
\text { kerja/aktifitas sehari-hari }\end{array}$ \\
\hline 5 & $\begin{array}{l}\text { Menyatakan keinginan dengan } \\
\text { keterangan tempat }\end{array}$ \\
\hline
\end{tabular}

\section{Model Visualilasi Proses}

Permodelan visual membantu untuk menangkap struktur dan kelakuan dari objek, mempermudah penggambaran interaksi antara elemen-elemen dalam sistem dan mempertahankan konsistensi antara desain dan implementasi dalam pemrograman. Pemodelan visual menggunakan usecase diagram untuk menunjukkan fungsionalitas suatu sistem atau kelas dan bagaimana sistem berinteraksi sebagai alat bantu komunikasi, pembelajaran, dan terapi bagi anak dengan autisme.Story Board

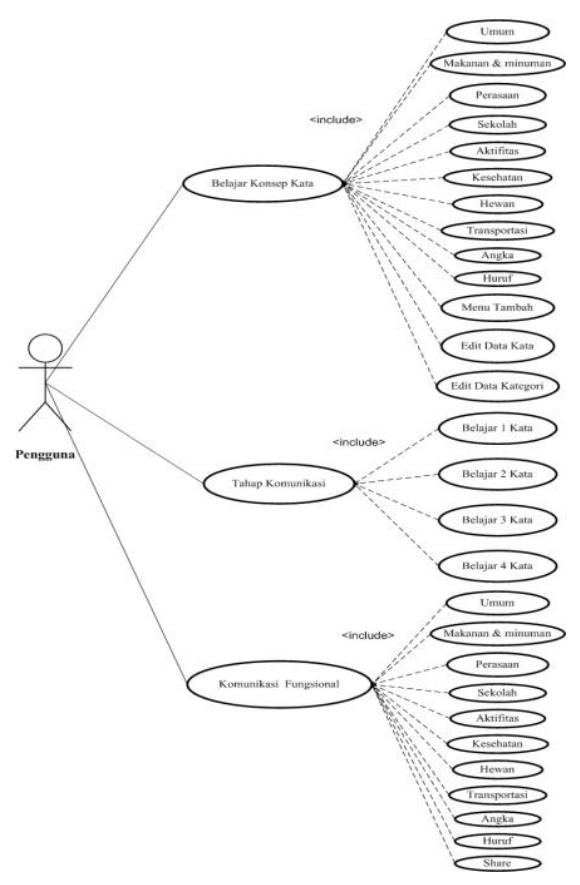

Gambar 4. Usecase Diagram

Tabel 2. Deskripsi Usecase dan Aktor Pengguna Pada Aplikasi

\begin{tabular}{|c|c|c|c|}
\hline No & Actor & $\begin{array}{l}\text { Use } \\
\text { Case }\end{array}$ & Deskripsi \\
\hline 1 & $\begin{array}{l}\text { Terapis/ } \\
\text { Orang } \\
\text { Tua }\end{array}$ & $\begin{array}{l}\text { Belajar } \\
\text { Konsep } \\
\text { Kata }\end{array}$ & $\begin{array}{l}\text { Terapis/Orang } \\
\text { Tua dapat } \\
\text { mengajarkan } \\
\text { pasien konsep } \\
\text { kata. Konsep } \\
\text { kata berfungsi } \\
\text { untuk } \\
\text { mengenalkan } \\
\text { pasien Jenis } \\
\text { kata } \\
\text { benda,kata } \\
\text { sifat, kata } \\
\text { kerja, } \\
\text { mengenal } \\
\text { objek, tempat, } \\
\text { dan perasaan, } \\
\text { Belajar } \\
\text { Konsep Kata }\end{array}$ \\
\hline
\end{tabular}


Volume 9 No. 3 |November 2019: 53-64

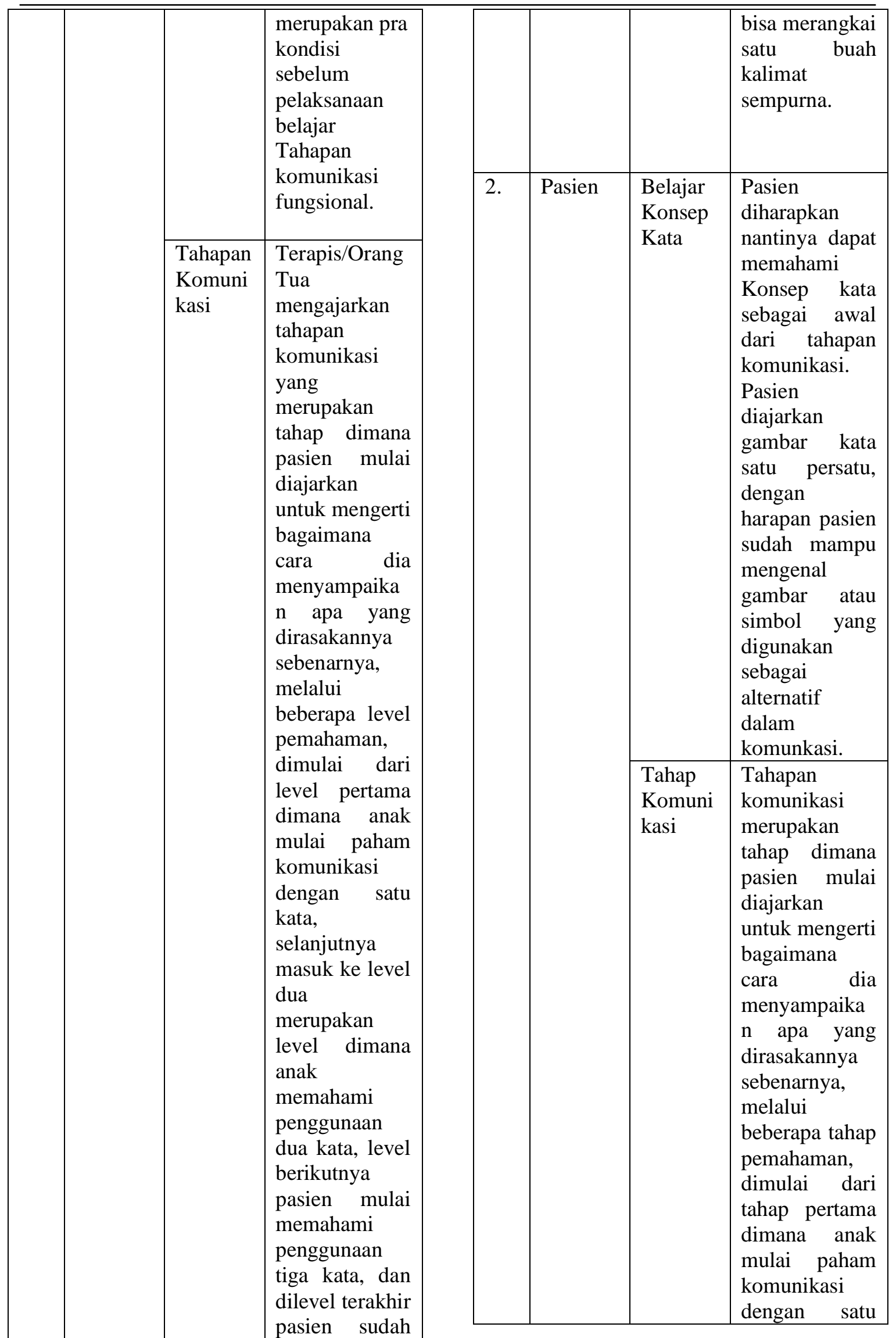




\begin{tabular}{|c|c|}
\hline & $\begin{array}{l}\text { kata, } \\
\text { selanjutnya } \\
\text { masuk ke level } \\
\text { dua } \\
\text { merupakan } \\
\text { level dimana } \\
\text { anak } \\
\text { memahami } \\
\text { penggunaan } \\
\text { dua kata, level } \\
\text { berikutnya } \\
\text { pasien mulai } \\
\text { memahami } \\
\text { penggunaan } \\
\text { tiga kata, dan } \\
\text { dilevel terakhir } \\
\text { pasien sudah } \\
\text { bisa merangkai } \\
\text { satu buah } \\
\text { kalimat } \\
\text { sempurna. }\end{array}$ \\
\hline $\begin{array}{l}\text { Komuni } \\
\text { kasi } \\
\text { Fungsio } \\
\text { nal }\end{array}$ & $\begin{array}{l}\text { Pada tahap ini } \\
\text { anak sudah } \\
\text { sampai pada } \\
\text { titik dia } \\
\text { mampu } \\
\text { merangkai } \\
\text { kalimat } \\
\text { sempurna } \\
\text { untuk } \\
\text { mengutarakan } \\
\text { apa yang } \\
\text { diinginkan dan } \\
\text { dirasakan. }\end{array}$ \\
\hline
\end{tabular}

\section{Story Board}

Story board ini dibuat agar dapat memudahkan dalam memahami alur penggunaan dari aplikasi. Story board berisi arahan-arahan dalam penggunaan aplikasi. Berikut Story Board dari Aplikasi alat bantu komunikasi, pembelajaran dan terapi bagi pasien ASD (Autism Spectrum Disorder).

Tabel 3. Story Board Aplikasi

\begin{tabular}{|c|c|c|}
\hline No & $\begin{array}{l}\text { Tampilan } \\
\text { Halaman }\end{array}$ & Keterangan \\
\hline 1 & 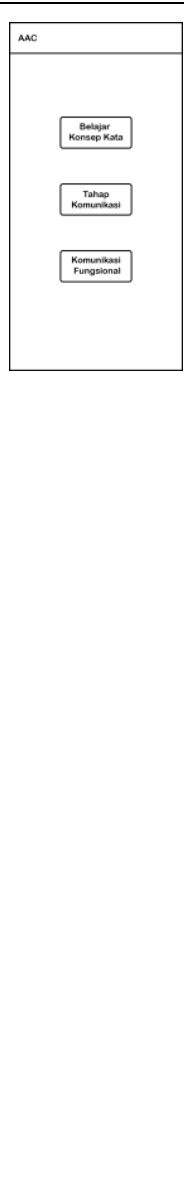 & $\begin{array}{l}\text { (Scene 1) } \\
\text { Setelah Aplikasi } \\
\text { dibuka maka akan } \\
\text { muncul tampilan } \\
\text { menu utama. } \\
\text { Aplikasi memiliki } \\
\text { tiga menu utama } \\
\text { yaitu: } \\
\text { 1. Button menu } \\
\text { belajar konsep } \\
\text { kata (apabila di } \\
\text { klik/disentuh } \\
\text { maka akan } \\
\text { muncul } \\
\text { tampilan scene } \\
\text { 2) } \\
\text { 2. menu tahap } \\
\text { komunikasi. } \\
\text { apabila Button } \\
\text { di klik/disentuh } \\
\text { maka akan } \\
\text { muncul } \\
\text { tampilan scene } \\
\text { 3) } \\
\text { Button menu } \\
\text { komunikasi } \\
\text { fungsional }\end{array}$ \\
\hline 2. & 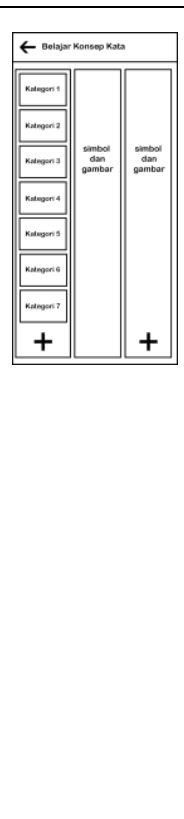 & $\begin{array}{l}\text { (Scene 2) } \\
\text { Tampilan menu } \\
\text { Belajar Konsep kata } \\
\text { 1. Apabila Button } \\
\text { kategori } \\
\text { diklik/disentuh } \\
\text { maka akan } \\
\text { muncul } \\
\text { simbo/simbol } \\
\text { dan gambar. } \\
\text { 2. Selanjutnya } \\
\text { apabila Ketika } \\
\text { Button } \\
\text { gambar/simbol } \\
\text { di klik/disentuh, } \\
\text { maka gambar } \\
\text { mengeluarkan } \\
\text { speech (suara). }\end{array}$ \\
\hline
\end{tabular}


Volume 9 No. 3 |November 2019: 53-64

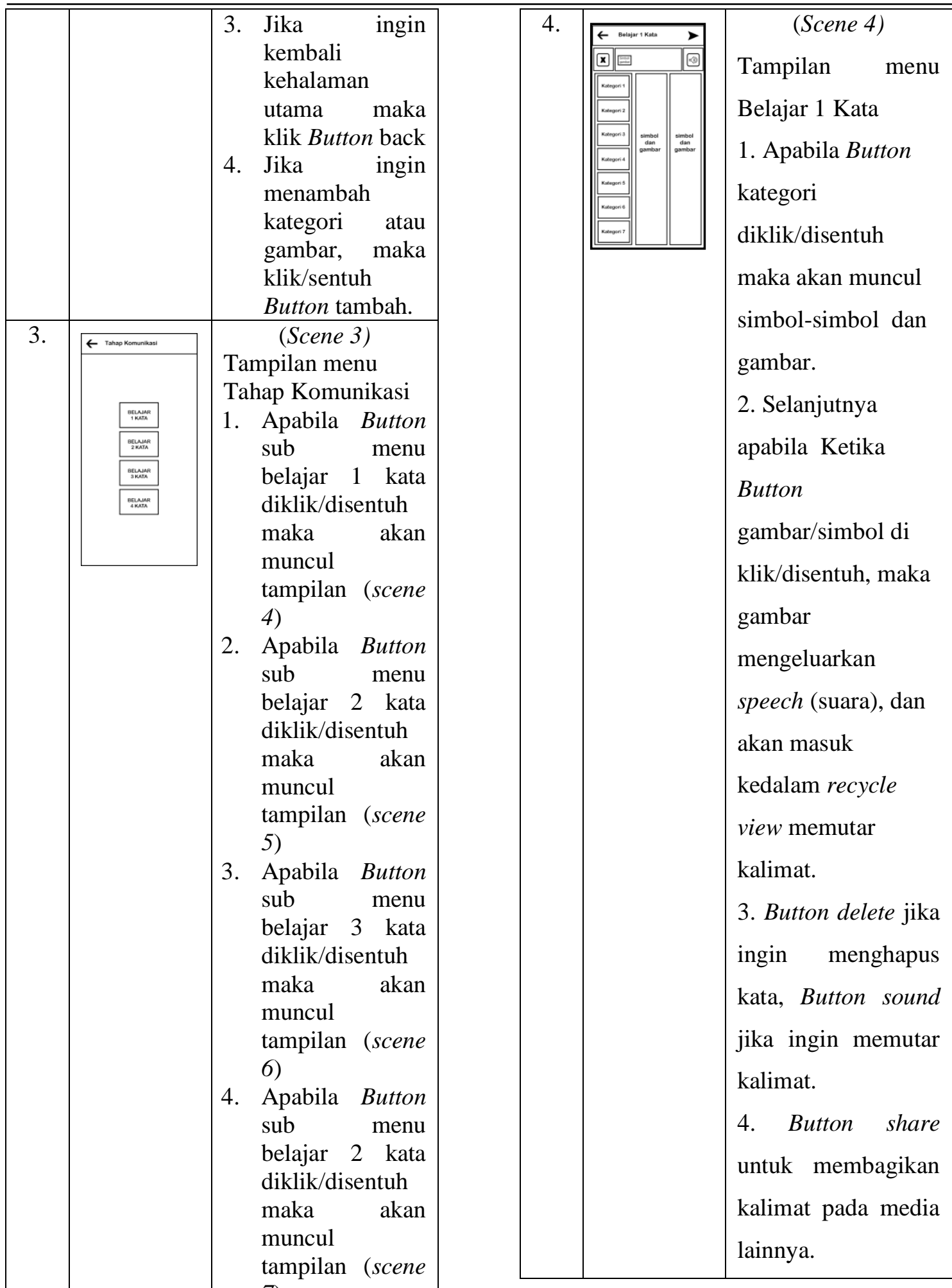

5. Jika ingin kembali kehalaman utama maka klik Button back 
Volume 9 No. 3 |November 2019: 53-64

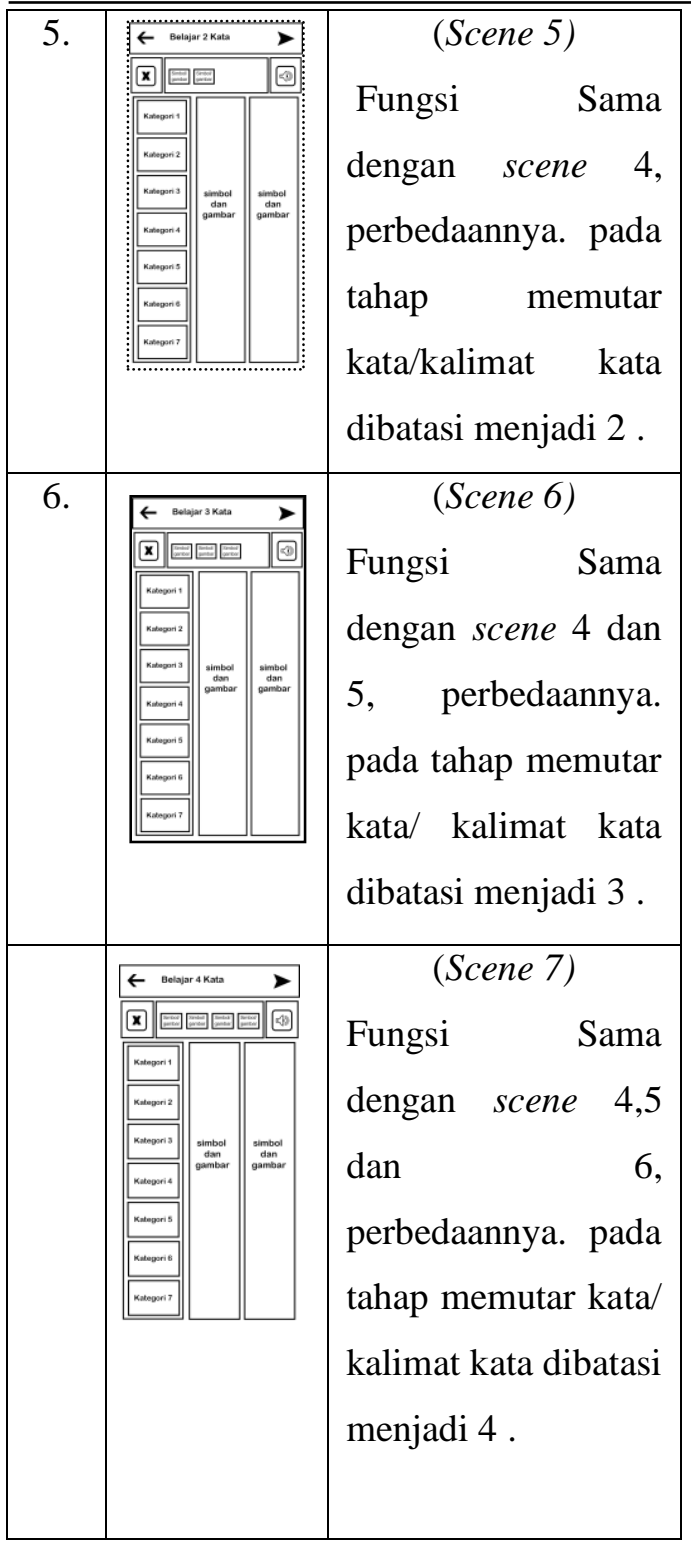

\section{Implementasi Sistem}

Implementasi sistem merupakan tahapan dan penggunaan desain perancangan yang telah dibuat. Adapun implementasi sitem terdiri dari tampilan menu utama, tampilan menu konsep kata, menu tahap komunikasi, menu belajar satu kata, menu belajar dua kata, menu belajar tiga kata, menu belajar empat kata, menu komunikasi fungsional, form tambah kategori, form tambah kata, dan menu share. Pada saat buka aplikasi maka akan menampilkan halaman menu utama seperti pada gambar IV.

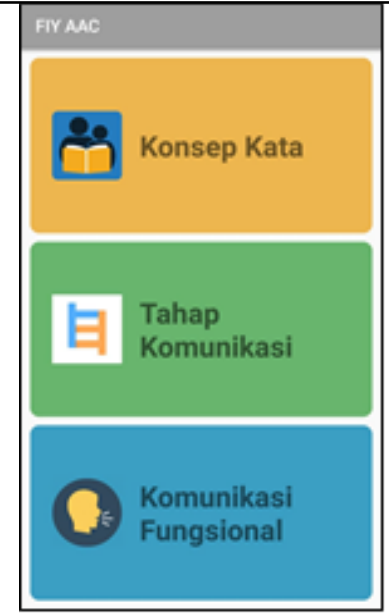

Gambar 5. Tampilan menu utama

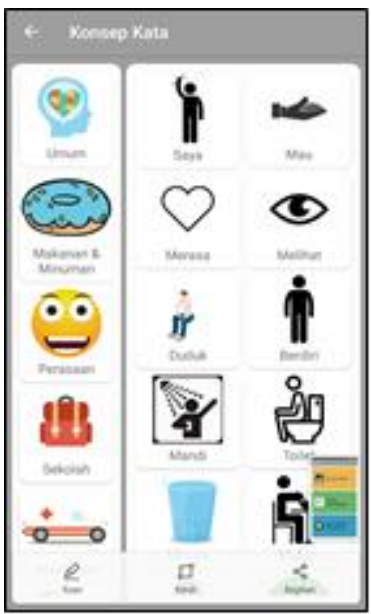

Gambar 6. Menu konsep kata

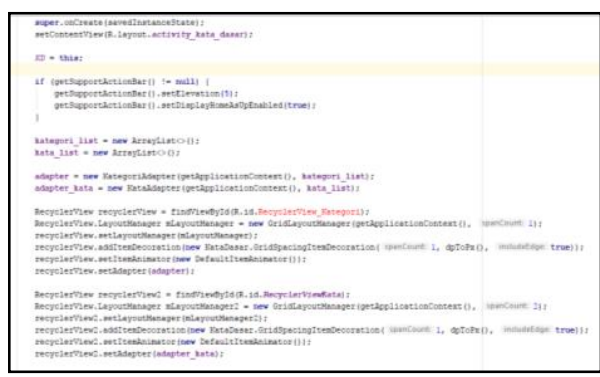

Gambar 7. Code Tampilan Menu Konsep Kata 
Volume 9 No. 3 |November 2019: 53-64

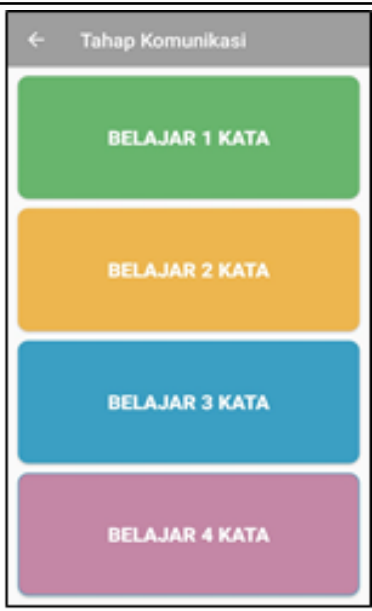

Gambar 8. Menu tahap komunikasi

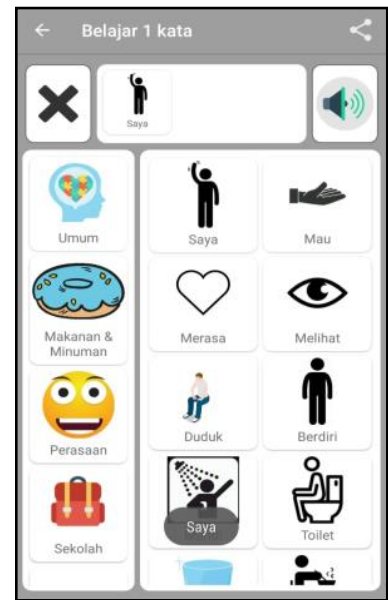

Gambar 9. Menu Belajar Satu Kata

Jika button tahap komunikasi belajar 2 kata di sentuh/diklik maka akan muncul tampilan seperti gambar 10, pada tahap ini komunikasi dibatasi menjadi 2 kata. Button tahap komunikasi belajar 3 kata di sentuh/diklik maka akan muncul tampilan seperti gambar 11, pada tahap ini komunikasi dibatasi menjadi 3 kata.

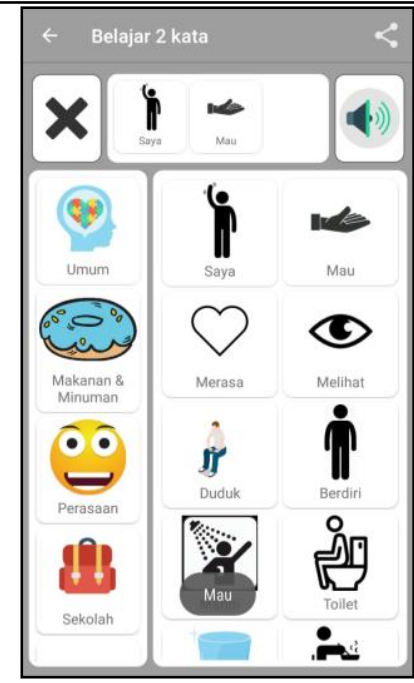

Gambar 10. Menu Belajar Dua Kata

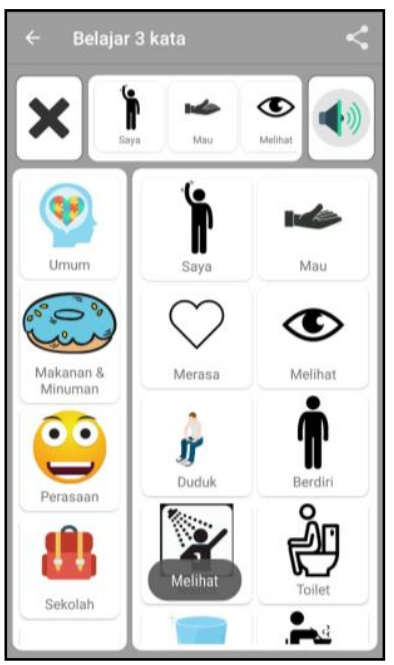

Gambar 11. Menu Belajar Tiga Kata

Button tahap komunikasi belajar 4 kata di sentuh/diklik maka akan muncul tampilan seperti gambar 12 , pada tahap ini komunikasi dibatasi menjadi 4 kata. Button tahap komunikasi fungsional di sentuh/diklik maka akan muncul tampilan seperti gambar 13, pada tahap ini komunikasi dibatasi menjadi 10 kata, pada menu ini anak sudah dianggap paham komunikasi. 


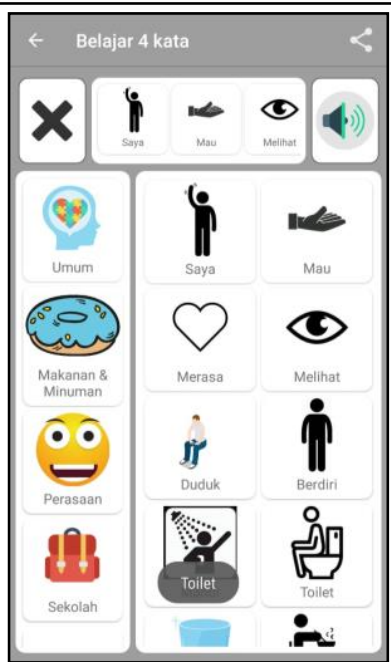

Gambar 12. Menu Belajar Empat Kata

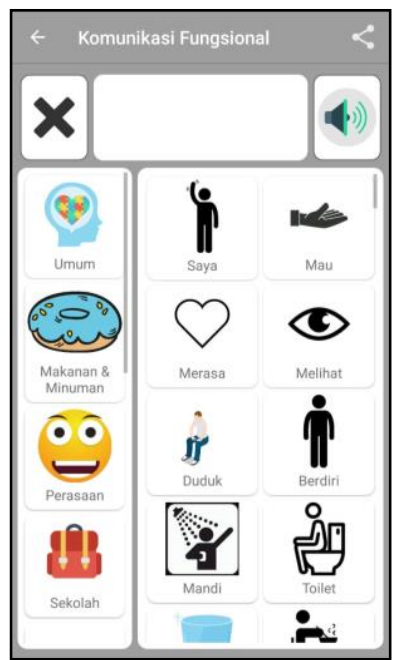

Gambar 12. Menu Komunikasi Fungsional

Hasil validasi kuisioner pengujian aplikasi pada tabel 4.13 oleh responden yang terdiri dari orang tua, guru dan terapis, menunjukkan kevalidan aplikasi mobile sebagai alat bantu komunikasi, pembelajaran dan terapi bagi pasien autism spectrum disorder mencapai $82 \%$, denga ratarata skor pada indeks 4.088 dengan skor maksimal 5. Tingkat kevalidan berada pada kriteria baik
Tabel 4. Hasil Pengujian Aplikasi

Kuesioner

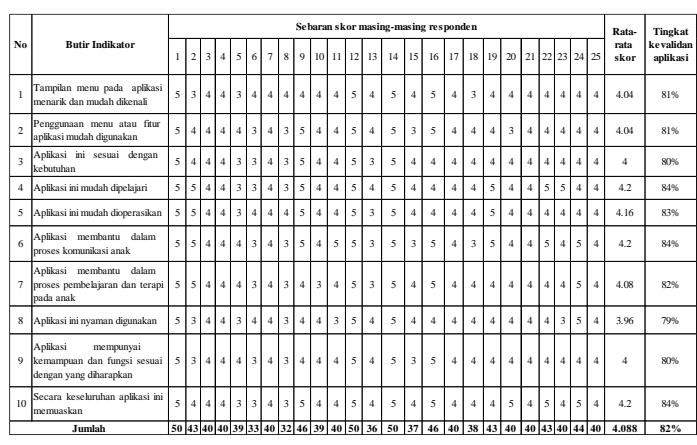

\section{Kesimpulan}

Autism Spectrum Disorder (ASD) merupakan gangguan perkembangan neurobiologis yang mempengaruhi fungsi otak sehingga anak kesulitan untuk berinteraksi dan berkomunikasi dengan dunia luar. Gangguan autisme tidak dapat disembuhkan, namun dengan diterapi secara teratur, perilaku anak autisme dapat mendekati anak normal lainnya. Dalam perancangan aplikasi alat bantu komunikasi, pembelajaran dan terapi bagi pasien ASD ini, banyak aspek yang harus dipelajari terkait dengan anak autisme itu sendiri, materi dan cara penyampaian yang sesuai untuk diberikan kepada mereka, dan aspek desain yang digunakan agar media dapat tersampaikan dengan baik dan efektif. Aplikasi dapat membantu dan mempermudah anak autisme mengekspresikan emosinya. Aplikasi yang dilengkapi dengan fitur gambar dan suara mempermudah anak autisme dalam proses belajar. Dengan adanya fitur pengenalan angka dan huruf dapat menjadi alternatif pembelajaran selain buku sehingga lebih meminimalisir biaya. Fitur komunikasi, belajar, dan terapi dalam satu aplikasi dapat memberikan berbagai kemudahan dan manfaat untuk anak autisme.

Saran untuk pengembangan aplikasi komunikasi, pembelajaran dan terapi bagi pasien ASD adalah Mengembangkan aplikasi komunikasi, pembelajaran, dan terapi untuk penderita autisme dengan menambahkan sensor gerak (mata) bagi 
anak autisme yang fungsi sensorisnya tidak dapat berfungsi total (tidak bisa menggerakkan tangan,kaki, atau kepala). Penambahan fungsi aplikasi untuk mengatur image size. Penambahan fungsi aplikasi untuk mengatur mengganti posisi image/kategori. Penambahan fungsi aplikasi yang memungkinkan untuk memanipulasi suara.

\section{Daftar Pustaka}

[1] Chouhan, V.L., Sharma, P. 2017. Behavioral Interventions in Autism. The InternationalJournal of Indian Psychology. ISSN 2348-5396. Volume 4, Issue 2, No. 85, DIP: 18.01.010/20170402

[2] YPAC, Buku Pedoman Penanganan dan Pendidikan Autisme. 2013

[3] Naguib, B., Anne, M., Bruck, S., Costley, D. 2015.Augmentative and alternative communication for children with autism spectrumdisorder: an evidence-based evaluation of theLanguage Acquisition through Motor Planning (LAMP) programme. Cogent Education, 2 (1). 1045807/11045807/25. ISSN 2331-186X

[4] Aprilia,D., Asahar J.,Pudji H. 2014. Sistem Pakar Diagnosa Autisme Pada Anak. Jurnal Rekursif, Vol. 2 No. 2, ISSN 2303-0755

[5] Chang, K.,Zaroff,C. M. 2017. Applied Behavior Analysis in Autism Spectrum Disorders in China and Hong Kong. Acta Psychopathologica. ISSN 24696676. Vol. 3 No. 5: 52. DOI: 10.4172/2469-6676.100124

[6] Mustaqball, M. S.,Firdaus, R.F., Hendra.,R. 2015. Pengujian Aplikasi Menggunakan Black Box Testing Boundary Value Analysis (Studi Kasus: Aplikasi Prediksi Kelulusan SNMPTN). Jurnal Ilmiah Teknologi Informasi Terapan Volume I, No 3. ISSN: 2407-3911

[7] Poernomo, M. H., Winarno, W. W., Sukoco. 2016. Perancangan Multimedia
Pembelajaran untuk Terapi Anak Berkebutuhan Khusus. SMATIKA Jurnal Volume 06 Nomor 01, ISSN: 2087-0256 